\title{
Air-to-air heat pump: review of recent advances and future potential
}

\author{
Nicolas Serey ${ }^{1, *}$, Darem Ahmad ${ }^{1}$, and Hussam Jouhara $^{1}$ \\ ${ }^{1}$ College of Engineering, Design and Physical Sciences, Brunel University London, Uxbridge, \\ Middlesex UB8 3PH, UK
}

\begin{abstract}
As the demand for energy is increasing and due to more focus on the utilization of low impact energy heat sources, heat pumps are a renewable energy technology that transfers thermal energy from one place to another. Heat pumps are used in various applications such as space heating, space cooling, heating water and many others. Heat pumps have many configurations but in essence they compose of components which are found in all units. The framework for 2030 climate and energy policy has decided that greenhouse emissions must be reduced by $40 \%$. This has therefore, increased the need to utilize low grade energy. Heat pumps have the capability to utilize the upgrade of low grade energy and reuse it within any domestic and industrial application. This paper will explain the working principle of an air-to-air heat pump, describing the different configurations, and evaluate the performance of such systems.
\end{abstract}

\section{Introduction}

Space heating and cooling account for the majority of domestic energy consumption in buildings, along with hot water. For many countries, this energy is still derived from fossil fuels and as not only fossil fuels are finite in quantity, they are environmentally unfriendly due to the release of CO2 which leads to climate change [1]. Therefore, from 2012/27 European Energy Efficiency Directive [2], it backed the use of renewable energy sources for residential energy consumption. This has significantly increased the interest in heat pump systems as an alternative option for space heating in homes. Later, EU's 2030 climate and energy framework has decided that greenhouse emissions must be reduced by $40 \%$ by 2030 [3].

Many research studies have been carried out to investigate the saving potential of an air heat pump system in comparison with alternative heating systems. Bojic et al. [4] estimated that natural gas boiler used for heating and air conditioning systems for cooling has the highest energy efficiency whilst also having the best economy, and the lowest environmental impact. This was in an office building based in Serbia. M. S. Torekov et al. [5] showed that heat pump systems are generally more economically viable than natural gas furnace, direct electric heating, and oil furnace for a single-family house, a two bed family house, clustered houses with 5 and 8 units and an apartment building.

\footnotetext{
* Corresponding author: Nicolas.Serey2@brunel.ac.uk
} 
Other studies have shown to what extent the heating performance of the HPS within buildings can reduce greenhouse gas emissions and improve energy efficiency. For an indoor sports hall in Turkey, Balta [6] observed that, when compared with an air HP, the conventional boiler has the lowest energy efficiency. A key task when selecting an adequate heating system is to identify the impact on the economic advantage for customers. Wu et al. [7] showed that, compared to conventional boiler, HPS are energy and economically feasible if properly designed according to the heating period and the energy price in the local area.

Thermal recovery of heat from exhaust air, carried out with either active or passive systems, has been widely dealt with in literature [4-7] and will become increasingly more important, considering stricter laws and legislations. Therefore, this paper will go through air-to-air heat pump mechanism of action, but more importantly discuss the state-of-the-art on this topic and evaluate the performance of such system for recovery of heat and utilizing it for applications such as space heating and cooling.

\section{Thermodynamic cycle of a heat pump}

This section will provide an overview of the thermodynamic cycle of a basic heat pump. Essentially, all heat pumps consist of this type of cycle.

For optimum performance, the heat pump must extract as much heat from a low grade heat source as possible. In-terms of coefficient of performance (COP), it is desirable to have a value that is as high as possible. The equation below (1) is derived from the basic reversed Carnot cycle. The proposed system shown in Fig. 1 shows the operation of a vapour compression cycle.

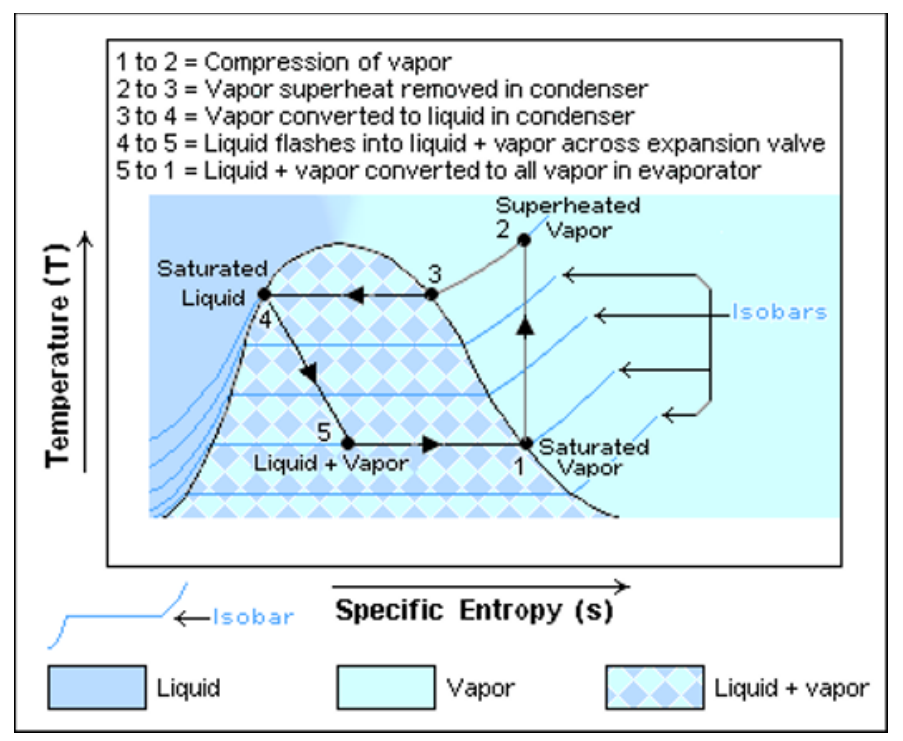

Fig. 1. Vapour compression graph for a basic refrigeration cycle.

The basic configuration of any heat pump in-terms of thermodynamic cycle is shown in Fig. 1. As the diagram shows, points 1 to 2 is the operation line of the compressor. This produces high temperature, high pressure refrigerant. Points 2 to 4 is where heat is rejected in the condenser and refrigerant changes phase from a vapour to a liquid. Points 4 to 5 is where the refrigerant goes through the expansion valve causing a reduction in pressure and 
temperature and thus the liquid to flash. Points 5 to 1 show the operating line in the evaporator. This is where the refrigerant absorbs heat from the surrounding, causing a phase change from a liquid into a vapour.

$$
C O P=\frac{\text { Useful energy output }}{\text { Work done by the compressor }}
$$

\section{Performance evaluation and discussion}

Several configurations of air-to-air heat recovery exchanger exist. Mardiana and Riffat [7] classified these systems on their design characteristics: fixed-plate; rotary wheel, heat pipe and run around coil (this is a nearly passive device). In general, there is a lack of robust data on the conditions in "real installations". Therefore, this influences the reliability and seasonal efficiency.

Appropriate design, installation and commissioning of a heat pump dictates its performance. If any part of these have not been carried out properly, then the performance will be impacted significantly.

Another parameter that is usually used in comparison of heat pump is the seasonal performance factor or SPF which is defined as follows:

$$
S P F=\frac{\text { Seasonal heating capacity }}{\text { Heating electricity input }}
$$

However, SPF is highly dependent on outside temperatures, installation method, and other factors. Therefore, in this study COP will be used to evaluate the performance of heat pumps systems.

A study conducted by Liu et al [8] has shown that a solar-heat pump performs better than a single air source heat pump by as much as $20 \%$ in-terms of unit heat capacity and COP. However, the performance difference was greater when ambient temperature was $-5^{\circ} \mathrm{C}$ in comparison to when it was $7^{\circ} \mathrm{C}$. The percentage improvement was $27 \%$ in-terms of unit heat capacity and COP increase of $45.5 \%$.

The following table shows the typical cost for heating systems in the UK. Gas and oil boilers are yet the cheapest method for space heating. However, with the increased trend in lowering greenhouse emissions and finding an efficient heat recovery method, heat pumps are the way forward but currently this comes at a high price depending on the size and configuration of the system.

Table 1. Typical capital costs for conventional heating systems and heat pump systems [9].

\begin{tabular}{|c|c|c|}
\hline $\begin{array}{c}\text { Heating and hot } \\
\text { water system }\end{array}$ & $\begin{array}{c}\text { Typical capital cost } \\
(\mathfrak{f})\end{array}$ & $\begin{array}{c}\text { Annual running cost } \\
\text { savings compared } \\
\text { with electricity (£) }\end{array}$ \\
\hline Gas boiler & 2,500 & - \\
\hline Oil boiler & 3,000 & - \\
\hline GSHP & $9,000-17,000$ & 420 \\
\hline ASHP & $6,000-10,000$ & 300 \\
\hline
\end{tabular}

The capital cost can be significantly reduced when heat pump systems become more common as manufacturers will produce according to demand and price according to competition. Besant and Simonson [10] air-to-air heat recovery can reduce capital costs and energy consumption of auxiliary heating and cooling equipment. 
A research study carried out by Wallin et al. [11] has shown that for a typical case in Stockholm, the heat recovery using a conventional air-to-air heat pump can be up to $47 \%$. This figure was improved to $65 \%$ by retrofitting a run-around coil to the heat pump system. The payback for the system investigated was calculated to be approximately 6 years, which can be considered long.

A study carried out by Fucci et al. [12] showing an integrated mechanical ventilation system with heat pump. The system showed an average overall coefficient of performance COP of 9.5, 8.9 and 6.6 at $\mathrm{T}_{\mathrm{O}}=0^{\circ} \mathrm{C}, 5^{\circ} \mathrm{C}$ and $10^{\circ} \mathrm{C}$ (outdoor air temperature), respectively. The amount of heat recovered was $86.2 \%$, making it possible to reduce the use of the heat pump in attenuation mode. This will reduce the duty of the compressor and thus will make the operation even more efficient.

Thalfeldt et al. [13] has investigated the two main methods to ensure good air quality and energy efficiency in renovated apartments in cold climate. The two methods are mechanical supply and exhaust ventilation with heat recovery (HRV) and exhaust air heat pump (EAHP). It was found that EAHP eliminates the district heating consumption during summer. The SPF value from the EAHP was 3.6 indicating a very good performance in-terms of energy output to electricity input. However, there was no mention of exact capital cost of the system.

A research study by Deng et al. [14] have carried out field tests and evaluation on 32 heat pump systems used for space heating. The results from this study are interesting as some suggestions made are advantageous to the performance of the heat pump systems. These include obtaining a high temperature heat source which means location of the evaporator is very important, energy efficiency could be improved by adjusting the system to match the demand, and adopting a decentralized system could be more beneficial as transmitting electricity is much easier than distributing hot water with almost no losses.

It must be noted that during the review of scientific literature, it was rare to find studies showcasing all of the test data, temperature profiles, heating demand etc. This makes it difficult to evaluate the papers adequately and have an overview of the conditions used, energy demand, and requirements needed. Many studies have not stated the refrigerant used, as many refrigerants are being phased out, it will be useful to select the new low Global warming potential (GWP) and 0 Ozone depletion potential (ODP). Many of the new refrigerants that are to replace the conventional refrigerants, such R22, are flammable. This poses a new risk for when such heat pump units are to be installed domestically and/or industrially. Some refrigerants have been developed to have the desired characteristics but as they are new, compatible compressors and other components are difficult to find and can be very expensive. Each refrigerant has a certain heating/cooling capacity as well as pressure ranges which must not be exceeded. Therefore, when discussing future use and potential of such system, these parameters must be considered profoundly.

\section{Adoption of "Smart" heat pump systems}

With technological advances, it was only till recently since that conventional gas fired boilers were made "smart". "Smart" refers to systems that can be controlled wirelessly using an application on a smart phone which will have special operational features such as location detection to heat up the house for instance. The biggest advantage of smart systems is that it is very convenient for occupiers to control the heating throughout the day. The conventional heat programming system where a user selects when the heating is turned on or off is very rigid and will cause energy loss when it is not needed for example when house occupiers leave the home. Disabling such system and enabling them again is inconvenience to many. Therefore, the adoption of smart but also intelligent heating/ventilation systems can be an ideal feature that can potentially save more energy. 
The same development can be predicted for heat pumps as there are many advantages beyond the energy saving due to vacancy automatic turn off option. Especially in the case of extract air heat pumps (EAHP) that can control the air change rate with dampers. With the addition of a few sensors to monitor the air quality levels by measuring the $\mathrm{CO}_{2}$ levels or $\mathrm{RH}$, the heat pumps become capable of adjusting to the needs of the occupants. It could provide night time ventilation cooling, saving the user to run the heat pump as a refrigeration system for a few hours if the house is well insulated. Another very important advantage would be learning that can be done with a large enough number of these smart heat pumps. A more accurate sizing of future air conditioning installations can be achieved by comparing the heating and cooling demands with the size of the building, number of occupants and meteorological factors of the area. This designing step is the most critical to get maximum energy saving. Indeed, an undersized heat pump would oblige the occupant to use a second stage heating or cooling, usually electric devices with poor energy efficiency compared to the heat pump (an electric heater has a COP equivalent of 1). Whereas an oversized heat pump will run shorter cycles at lower efficiency, causing higher energy consumption, early compressor failures, and an increased use of high GWP refrigerant with no benefit.

It could also be imagined that future heat pump could communicate and receive weather forecast information to predict when to operate in cooling or heating mode. Thus, avoid the use of costly and inefficient second heating or cooling stage. A big enough grid of interconnected heat pump would be able to turn on or off to respond to the electric grid fluctuations. If renewable energy is to take a bigger part in the energy mix, heat pump systems are relatively more reliable than solar or wind sourced electricity production as they are mostly intermittent. The end user of the smart heat pumps could save on their electricity bill or operating costs by storing this energy in the form of heat or cooling in the house of the occupants in prevision for the day or next few hours.

\section{Conclusion}

Over the past few years, one of the most important issues of the international community has been the rate of energy consumption and the level of greenhouse gas (GHG) emissions throughout the globe. Recently, EU legislations are focusing more on the recovery of low grade heat and utilizing this energy. Heat pump systems provide a potential solution to meet the projected greenhouse emission limits. During the winter majority of the heat is derived from conventional gas fired boilers with no attention to the thermal energy that is lost to the outside.

Air-to-air heat pumps provide a recovery solution of the lost low grade heat whether it is in industries or homes. The recovered thermal energy can be used for a variety of applications such as space heating, hot water, air pre-heater in-case of industries. The studies investigated in this paper show that air-to-air heat pumps work efficiently but they have a drawback as the system capital cost is high. However, if manufacturers produce more heat pump components/systems due to higher demand, this will reduce the cost because of competition. Air-to-air heat pump systems are still at an early stage in their development. In-depth experimental studies showcasing system performances is scarce, making it difficult to evaluate the possible systems.

The heat pump systems can be optimized further by making them "smart systems". This will include temperature sensors, $\mathrm{CO}_{2}$ sensors, wind velocity sensors and dampers. The heat pump systems could potentially be used as ventilation systems, operating at set points to maintain comfortable environment. 


\section{References}

1. D. Ürge-Vorsatz, L. F. Cabeza, S. Serrano, C. Barreneche, K. Petrichenko, Renew. Sustain. Energy Rev. 41, 85-98 (2015)

2. European Parliament. Directive 2012/27/EU of the European Parliament and of the Council of 25 October 2012 on energy efficiency, amending Directives 2009/125/EC and 2010/30/EU and repealing Directives 2004/8/EC and 2006/32/EC. Off J Eur Union 2012;14/11/2012:1-56. doi:10.3000/19770677.L_2012.315.eng (2012)

3. O. Sartor, T. Spencer, I. Bart, P. E. Julia, A. Gawlikowska-Fyk, K. Neuhoff, The EU's 2030 Climate and Energy Framework and Energy Security (2014)

4. M. Bojić, D. Cvetkovic, J. Skerlić, D. Nikolić, H. Boyer, Performances of Low Temperature Radiant Heating Systems (Second Int. Conf. Build. Energy Environ. COBEE, 1-10, 2012)

5. M. Sørensen Torekov, N. Bahnsen, B. Qvale, Energy 32, 627-33 (2007)

6. M. Balta, Y. Kalinci, A. Hepbasli, 40 (2008)

7. A. Mardiana-Idayu, S. B. Riffat, Renew. Sustain. Energy Rev. 16, 1241-55 (2012)

8. F. Liu, L. Wang, Q. Wang, H. Wang, Procedia Eng. 205, 3873-8 (2017)

9. H. Pumps, Energy Saving Trust (2019)

10. A. S. H. Rae, B. R. W. Besant, P. Eng, C. J. Simonson, Air-To-Air Energy Recovery 2000 (2019)

11. J. Wallin, H. Madani, J. Claesson, 90, 258-65 (2012)

12. F. Fucci, B. F. G. P. Catalano, Energy Build. (2016)

13. M. Thalfeldt, J. Kurnitski, E. Latõšov, Appl. Therm. Eng. 128, 402-14 (2018)

14. J. Deng, Q. Wei, M. Liang, S. He, H. Zhang, Energy Build. 182, 172-86 (2019) 